\title{
Confirmação da ocorrência do gênero Oplismenopsis (Poaceae) no Brasil
}

\author{
ADRIANA GUGLIERI ${ }^{1,4}$, ILSI IOB BOLDRINI² e JOSÉ F.M. VALLS ${ }^{3}$
}

(recebido: 16 de fevereiro de 2006; aceito: 4 de janeiro de 2007)

\begin{abstract}
Confirmation of occurrence of the genus Oplismenopsis (Poaceae) in Brazil). The occurrence of Oplismenopsis Parodi in Brazil is documented, based on collections from Rio Grande do Sul. This paper presents the description, geographic distribution, environmental preferences and phenological data of its single species, Oplismenopsis najada (Hack. \& Arechav.) Parodi, now formally incorporated into the Brazilian flora, as a native species.
\end{abstract}

Key words - Brazil, flora, Gramineae, Oplismenopsis, Rio Grande do Sul

RESUMO - (Confirmação da ocorrência do gênero Oplismenopsis (Poaceae) no Brasil). A ocorrência de Oplismenopsis Parodi é documentada no Brasil, com base em coletas realizadas no Estado do Rio Grande do Sul. O trabalho apresenta a descrição e dados referentes à distribuição geográfica, preferências ambientais e fenologia de sua única espécie, Oplismenopsis najada (Hack. \& Arechav.) Parodi, agora formalmente incorporada à flora brasileira, como espécie nativa.

Palavras-chave - Brasil, flora, Gramineae, Oplismenopsis, Rio Grande do Sul

\section{Introdução}

Oplismenopsis Parodi pertence à subfamília Panicoideae e tribo Paniceae (Clayton \& Renvoize 1986) da família Poaceae. Apresenta espiguetas acrótonas articuladas abaixo das glumas, com dois antécios, o primeiro estaminado e o segundo, mais consistente que as glumas, com flor bissexuada. Trata-se de um gênero monotípico, cuja única espécie, Oplismenopsis najada (Hack. \& Arechav.) Parodi (Parodi 1937), havia sido anteriormente constatada na Argentina e Uruguai (Zuloaga \& Morrone 2003), sempre associada a ambientes úmidos e alagados.

Em nota bibliográfica publicada na Revista Sudamericana de Botánica sobre o trabalho de Parodi (1937), um autor apenas identificado por "P." (Anônimo 1938) mencionou que $O$. najada é comum nos banhados do oeste do Uruguai, Mesopotâmia Argentina

\footnotetext{
1. Universidade Federal do Mato Grosso do Sul, Centro de Ciências Biológicas e de Saúde, Departamento de Biologia, Caixa Postal 549, 79070-900 Campo Grande, MS, Brasil.

2. Universidade Federal do Rio Grande do Sul, Centro de Ciências Biológicas e de Saude, Departamento de Botânica, Av. Bento Gonçalves 9500, prédio 43433, sala 214, 91570-950 Porto Alegre, RS, Brasil.

3. Embrapa Recursos Genéticos e Biotecnologia/Cenargen. Caixa Postal 02372, 70770-900 Brasília, DF, Brasil.

4. Autor para correspondência: adrianaguglieri@ig.com.br
}

e Rio Grande do Sul. No entanto, Parodi (1937) não havia feito referência à ocorrência da espécie no Rio Grande do Sul, limitando sua distribuição conhecida apenas a Argentina e Uruguai. Considerando a similaridade ambiental, Valls (1973) enfatizou a probabilidade de ocorrência do gênero no Rio Grande do Sul, apesar da falta de comprovação em herbários, até então.

Recentes coletas de $O$. najada, realizadas pelos autores do presente artigo, bem como a localização de dois exemplares da espécie depositados no herbário ICN da Universidade Federal do Rio Grande do Sul e incorretamente identificados como pertencentes aos gêneros Panicum L. e Hymenachne P. Beauv., comprovaram a ocorrência desta espécie hidrófila no Brasil.

\section{Material e métodos}

O presente trabalho está baseado na revisão bibliográfica de floras regionais do Brasil e de países vizinhos, revisão de herbários regionais, coletas e observações de populações no campo, além de estudos exomorfológicos. É fornecida a descrição da espécie em estudo, bem como dados referentes à sua distribuição geográfica, preferências ambientais e fenologia. Os exemplares analisados foram coletados nas regiões fisiográficas sul-riograndenses designadas por Fortes (1959) como Campanha, Depressão Central, Encosta do Sudeste e Litoral, e encontram-se depositados nos herbários ICN, CEN, HAS, PACA, RB e SP. 


\section{Resultados e Discussão}

A partir da documentação obtida a campo e em herbários, confirma-se a ocorrência natural de Oplismenopsis najada no Brasil, tanto ao longo do Rio Uruguai, na bacia hidrográfica do Rio da Prata, de onde a espécie foi descrita, quanto na bacia hidrográfica do Rio Jacuí, em ilhas do Guaíba e às margens da Lagoa dos Patos.

Oplismenopsis najada (Hack. \& Arechav.) Parodi, Notas del Museo de La Plata, Bot. 2 (Bot 11): 4 fig. 1. 1937. $\equiv$ Panicum najadum Hack. \& Arechav., Anales Mus. Nac. Montevideo 1: 125, t. 7bis, 8. 1894. $\equiv$ Echinochloa najada (Hack. \& Arechav.) Parodi, Physis 8: 75. 1925.

Figura 1

Plantas perenes, estoloníferas, estolhos de 55-154 cm compr., decumbentes, flutuantes, radicantes nos nós inferiores e medianos, entrenós 4-8,5 cm compr., (3-)6-9 mm diâm.; nós claros ou escuros, glabros. Bainhas foliares glabras, violáceas; colo glabro. Lâminas foliares lanceoladas a oval-lanceoladas, (3-)6-9,5(-12,7) $\times(0,5-) 0,8-2,2(-2,8) \mathrm{cm}$, planas, base arredondada, cordada ou subcordada, não amplexicaule, ápice agudo, margem esparsamente escabra; face abaxial glabra; face adaxial glabra, às vezes esparsamente pilosa na base, próximo à lígula. Lígula membranoso-ciliada, (0,5-)0,8-1,5 mm compr. Panícula com espiguetas dispostas irregularmente ao longo de todos os ramos, laxa 10-14,5 × 4-10,5 cm; axilas glabras; ráquis glabra, às vezes escabra; pedicelos glabros, às vezes escabros. Espiguetas lanceoladas, 10,2-11,2 × 1-1,2 mm, glabras, esverdeadas, 1-2-floras; gluma inferior $(5,4-) 7-8,3 \mathrm{~mm}$ compr., $1 / 2-2 / 3$ do comprimento da espigueta, 1-3-nervada, aristada; gluma superior 10-10,5 mm compr., 7-nervada, aristada; antécio inferior estaminado, 3 estames; lema 6,6-8,3 mm compr., 7-nervado, aristado; pálea 5-5,2 mm compr., elíptico-lanceolada; antécio superior 4,5-5,4 × 1,1-1,6 mm, coriáceo, palhete, glabro; 3 estames; anteras 1,9-3,0 mm compr., violáceas; cariopse 3-3,6 × 1,4-1,7 mm, elipsóide, castanha; hilo elíptico.

Material examinado: BRASIL. RIo GRANDE DO SUL: Pelotas, Laranjal, 6-XII-1991, H.M. Longhi-Wagner et al. 2509a (ICN); Ibidem, Pontal da Barra, 25-III-1995, B. Irgang \& C. Gastal s.n. (ICN120411); Porto Alegre, Ilha Grande dos Marinheiros, 17-I-2002, A. Guglieri 139 (ICN); Rio Grande, estrada para Santa Isabel do Sul, $31^{\circ} 11^{\prime} 09,8$ ' S - 52 31'04,6" W, 25-XI-2004, I.I. Boldrini et al. 1263 (ICN); São
Lourenço do Sul, Lagoa dos Patos, 31²2’36,2" S 51 57 '47,0”' W, 16-XI-2003, J.F.M. Valls et al. 14900 (CEN, RB, SP); Uruguaiana, Barragem do Sanchuri, 29³2'53,0' S - 56 49'39,0”' W, 14-XII-1998 (estéril), J.F.M. Valls et al. 12247 (CEN, ICN); Viamão, Parque Estadual de Itapuã, Praia do Fora, $30^{\circ} 23^{\prime} 10,7^{\prime \prime} \mathrm{S}$ 51 01 '12,8” W, 10-XI-2005, R. Trevisan et al. 482 (ICN).

Fenologia: floresce e frutifica no Rio Grande do Sul de novembro a março.

Distribuição geográfica: Uruguai, Argentina e Brasil (Rio Grande do Sul).

Oplismenopsis najada é facilmente reconhecida, em seu ambiente natural, por seus colmos robustos providos de aerênquima, lâminas geralmente ovallanceoladas, de coloração vinácea na base, bem como no ápice das bainhas foliares, inflorescências laxas e espiguetas lanceoladas, com glumas e lema inferior aristados.

Segundo Rosengurtt et al. (1970), no Uruguai, O. najada ocorre deste Montevidéu até Colônia, de forma escassa, em arroios próximos ao Rio da Prata. Burkart (1969) relatou a ocorrência da espécie às margens dos rios Paraná e Uruguai, bem como em brejos do Delta e Rio da Prata na Argentina. De acordo com Cabrera (1970), a espécie foi constatada em lagoas e arroios na região nordeste daquele país, incluindo a província de Buenos Aires, e Carnevali (1994) destacou a importância desta espécie na formação de ilhas flutuantes ("camalotales") na Província de Corrientes. Da mesma forma, $O$. najada foi coletada e observada, no Rio Grande do Sul, em praias lacustres e áreas de brejo, bem como ao longo de canais de irrigação de lavouras de arroz, onde também formava densas e extensas populações flutuantes, algumas vezes, associada a outras espécies de hábito semelhante como Panicum elephantipes Nees ex Trin. e Paspalum repens P. J. Bergius.

No entanto, apenas uma das populações coletadas (Valls et al. 14247) vegetava em área vinculada à Bacia do Prata, na região fisiográfica da Campanha. As demais eram da bacia disjunta formada pelo Rio Jacuí e seus afluentes, localizando-se em ilhas no Delta do Jacuí ou mesmo em praias, como a de Itapuã, às margens do Lago Guaíba (Depressão Central) e ao longo da margem sudoeste da Lagoa dos Patos (Encosta do Sudeste e Litoral).

Embora a ocorrência da espécie no Rio Grande do Sul esteja bem documentada, os mecanismos de migração entre as bacias hidrográficas não podem ser inferidos. 

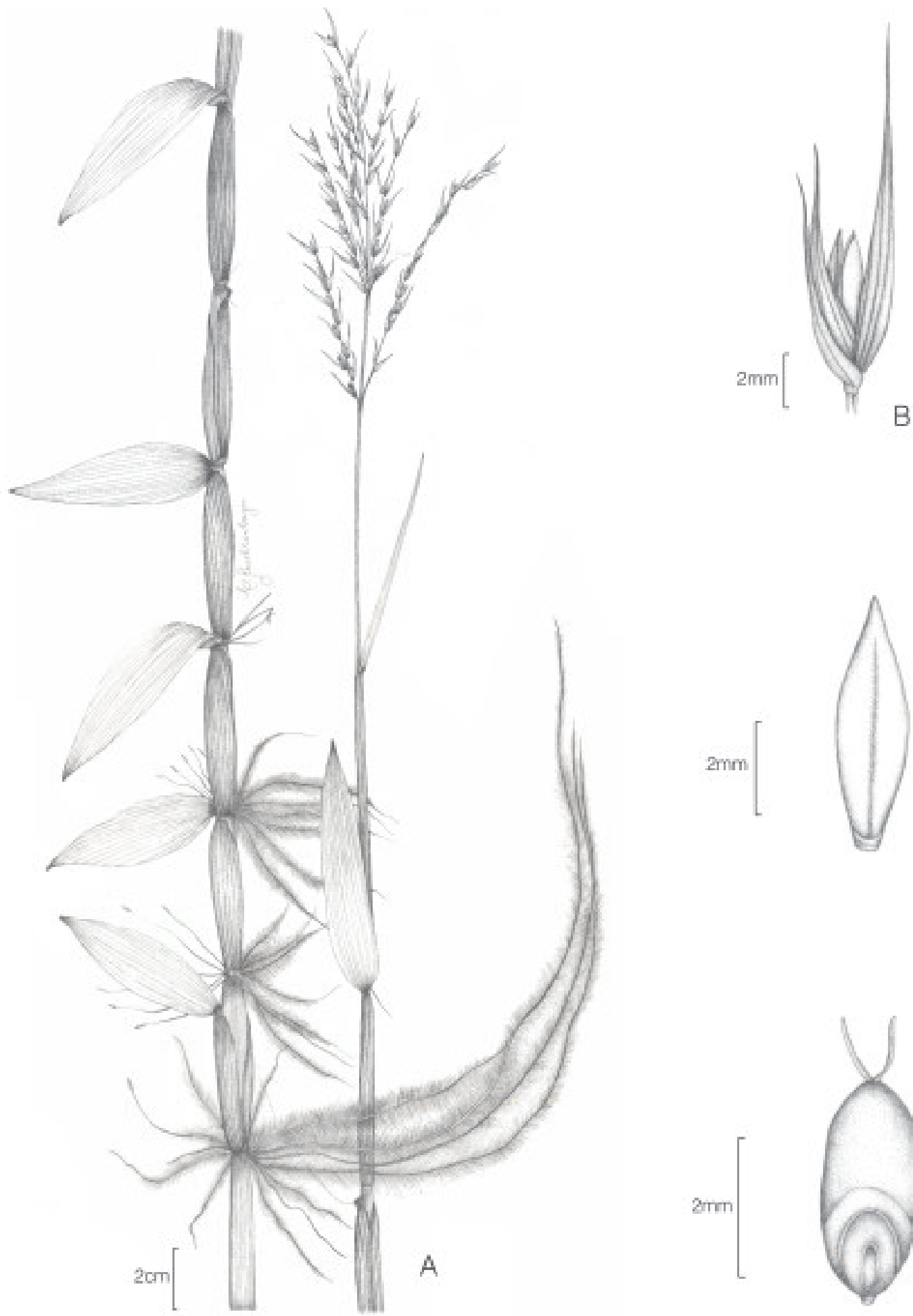

C
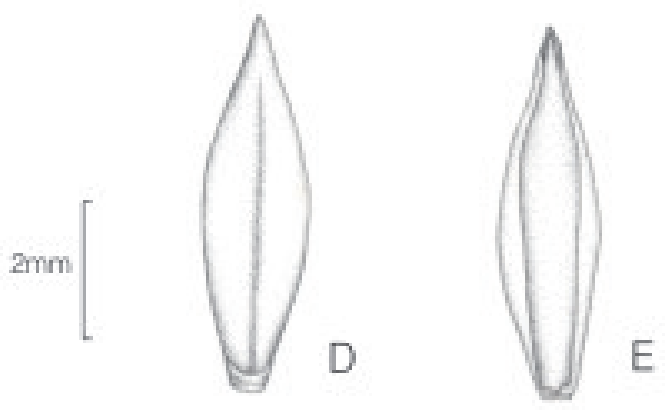

Figura 1. Oplismenopsis najada: A. Colmo e inflorescência; B. Espigueta; C. Pálea do antécio inferior; D. Antécio superior, vista dorsal; E. Antécio superior, vista ventral; F. Cariopse, vista dorsal; G. Cariopse, vista ventral (B. Irgang \& C. Gastal s.n., ICN120411).

Figure 1. Oplismenopsis najada: A. Culm and inflorescence; B. Spikelet; C. Lower pale; D. Upper floret, dorsal view; E. Upper floret, ventral view; F. Caryopsis, dorsal view; G. Caryopsis, ventral view (B. Irgang \& C. Gastal s.n., ICN120411). 
Agradecimentos - Os autores agradecem aos curadores dos herbários consultados.

\section{Referências bibliográficas}

ANÔNIMO. 1938. Bibliografia. Revista Sudamericana de Botánica 3:107-108.

BURKART, A. 1969. Flora de la Província de Entre Ríos. Parte II. Gramíneas. Colección Científica del INTA, Buenos Aires.

CABRERA, A.L. 1970. Flora de la Província de Buenos Aires. Parte II. Gramíneas. Colección Científica del INTA, Buenos Aires.

CARNEVALI, R. 1994. Fitogeografía de la Província de Corrientes. INTA, Corrientes.

CLAYTON, W.D. \& RENVOIZE, S.A. 1986. Genera Graminum. Grasses of the World. Royal Botanic Gardens, Kew.
FORTES, A.B. 1959. Geografia física do Rio Grande do Sul. Livraria do Globo, Porto Alegre.

PARODI, L.R. 1937. Gramíneas argentinas nuevas o criticas. Notas del Museo de La Plata 2:1-4.

ROSENGURTT, B., ARRILAGA-DE-MAFFEI, B. \& IZAGUIRRE-DE-ARTUCIO, P. 1970. Gramíneas Uruguayas. Universidad de la República, Montevideo.

VALLS, J.F.M. 1973. Notas sobre gramíneas do Rio Grande do Sul, Brasil: I. Citações novas para a flora sulriograndense e relação das tribos e gêneros com ocorrência confirmada. Iheringia 18:54-63.

ZULOAGA, F.O. \& MORRONE, O. 2003. Oplismenopsis. In Catalogue of New World Grasses (Poaceae): III. Subfamilies Panicoideae, Aristidoideae, Arundinoideae and Danthonioideae. (R.J. Soreng \& S.J. Pennington, eds.). Smithsonian Institution, Washington. Contributions from the United States National Herbarium 46:298-299. 